\title{
The performance of hydraulic jump over rough bed stilling basin consisting of cubic-shape elements
}

\author{
Jaafar Maatooq ${ }^{1}$, and Enass Taleb ${ }^{1}$ \\ ${ }^{1}$ Building and Construction Dept., University of Technology, Baghdad, Iraq
}

\begin{abstract}
Three groups of cubic roughness elements non-protruding to the flow were fixed with a specific configuration at the downstream of a stream lined lib sluice gate. The aim was to test the performance of the hydraulic jump under using such elements as appurtenances of stilling basin. The experimental works has been conducting to test; four different intensities, $\mathrm{I}=8 \%, 10 \%, 12 \%$ and $16 \%$; three width to height ratios, $\mathrm{We} / \mathrm{he}=0.75,1.5$ and 2 ; and three length to height ratios, Le/he $=0.75,2$ and 4 , of cubic elements made from waterproof stiff rubber. The test was performed under the incoming Froude number; F1 ranged between 2.7 to 9 . After analysing the experimental data one from the second group configuration gives a higher reduction of sequent depth ratio, $\mathrm{y} 2 / \mathrm{y} 1$ as compared with the depth ratio of the un-forced hydraulic jump which calculated by Belanger equation, this decreases arrived $20 \%$. Also greater relative energy has been dissipated, and the gain in dissipation (\%GED) ranged between 10.8-22.3\%.
\end{abstract}

\section{Introduction}

Hydraulic jumps are divided into two types according to the bed characteristics. The first is a classical hydraulic jump occur over a smooth bed and has been studied extensively by different researchers such as $[4,19,13,14,22]$. All these studies were based on comparison with Belanger equation. The second is formed over the so called roughness elements when different appurtenances are used to configure a roughness on stilling basin bed. This type is known as a forced jump and has been studied by many researchers [e.g., 4,23,2,20,8,21,10,5,9]. A hydraulic jump is extremely in turbulent, and the flow along it is rapidly varied. It is characterized by the development of largescale turbulence, surface waves and spray, and air entrainment. Normally any hydraulic jump should need a stilling basin in order to contain it and to dissipate more energy that mainly is excessive when accompanied with the high velocity through the structure (e.g., under a sluice gate). The stilling basin should be designed to confine the formation of the hydraulic jump, inducing more dissipation of kinetic energy, thereby avoiding or minimizing the damage ability downstream. However, the designer focusing on knowing the height of jump into a stilling basin that has been proposed in order to get a safe height of the side walls with a suitable free board, the less the sequent depth, y2 the shorter height of side wall need. These two advantages (i.e., more dissipation of surplus kinetic energy and reducing the sequent depth ratio) can be achieved by roughing the bed of stilling basin by specific elements. The variation in the expected advantage from the use of these appurtenances depends on many factors such as; type, shape, and configurations along with the hydraulic boundary conditions. Specifically, with the kind of roughness elements have been adopted in the present study, some of the relevant previous studies should review. [20], studied the effect of cubic elements as a roughness installed into bed at intensity $\mathrm{I}=10 \%$ on the length of rectangular hydraulic jump under different flow conditions. The aim was to obtain the optimum length of jump on a rough bed section for both engineering and economics terms. [21], studied the effect of horizontal rectangular roughness elements placed at the downstream of the sluice gate. Different intensities of roughness have been used in experiments ranging between 0 to $100 \%$, beside that different height of roughness he $=0.8,1.2,1.6$ and $2 \mathrm{~cm}$, and different roughened lengths, Lr ranged between 1.6 to $200.66 \mathrm{~cm}$ were adopted. The roughness parameters that produced the minimum length of jump and hence the minimum length of stilling basin from the hydraulic point of view were determined and specified. [10], carried out an experimental study on non-protruding prismatic roughness and he studied the effect of roughness type and arrangement on the length of the jump, energy dissipation, and tail water. The 
investigation was restricted to incoming Froude numbers ranging between 7.3 and 16.6. The results were compared with properties of jump occurring on the smooth bed. The analysis of experimental data showed that the length of the jump was obtained to be $40 \%$ less than in traditional (over smooth bed) jump, and the energy losses through the hydraulic jump ranged from $5 \%$ to $10 \%$ higher than those formed on smooth beds. Moreover, the tail water depth in a roughened bed was $20 \%$ lower compared to that formed on a smooth bed. [5], carried out an experimental study on non-protruding prismatic roughness and he has studied the effect of the varying upstream flow parameters, i.e. the initial Froude number, Fr1, and initial depth, y1, with the boundary roughness parameters, as the length ratio, pitch ratio, and roughness arrangement, on the characteristics of the hydraulic jump. [6], measured the characteristics of hydraulic jump (sequent depth and roller length occurring on bed roughness of closely crushed gravel particles cemented to the bottom. A new solution of the momentum equation for sequent depth ratio as a function of the initial Froude number and the proportion between the height of roughness and the initial depth of flow has been introduced. [25], studied, two types of natural bed roughness with crushed sedimentation materials 20 and $27 \mathrm{~mm}$ in size to show the effect of these roughness on the characteristics of hydraulic jump, including roller length, jump length, initial and sequent depths, relative energy losses through the jump, boundary stress, and shear stress. The roughness models were tested under 72 experiments with Froude numbers from 5 to 12.7. [11], carried out an experimental study on a rough bed consisting U-shape elements to find the best length and intensity of these elements on hydraulic jump characteristics. These elements fixed at the downstream of vertical gate equal twice the gate opening. The feature of the flow was tested under four different intensities I= $4.5,8,12$ and $18 \%$ and eight different lengths roughness used with a sufficient intensity. The $\mathrm{U}$-shape roughness has been compared with other roughened shapes, and the efficient performance was achieved using the U-shape roughness. The results show that the higher effect roughness intensity was $12.5 \%$ at which the relative sequent depth of jump (y2/y1) was reduced by $14-20 \%$ and minimized the relative length of the jump by 28 $47 \%$. In the present study, four different intensities, $\mathrm{I}=8 \%, 10 \%, 12 \%$ and $16 \%$; three width to height ratios, $\mathrm{We} / \mathrm{he}=0.75,1.5$ and 2 ; and three length to height ratios, Le/he $=0.75,2$ and 4 , of cubic elements made from waterproof stiff rubber have been adopted to show the effects of these arrangements on the characteristics of the hydraulic jump.

\section{Experimental works and procedure}

The experimental investigations were carried out by using a laboratory flume in the fluid laboratory of Building and Construction Engineering Department, UOT-Baghdad. The cross section of the flume was $0.3 \mathrm{~m}$ wide, $0.3 \mathrm{~m}$ deep, with a total length $15 \mathrm{~m}$. The steel plate walls added to the inlet part of the flume through $4 \mathrm{~m}$ length to rising the depth up to $0.6 \mathrm{~m}$, in order to ensure access sufficient heads upstream the stream lined lib sluice gate which is used as a control device to get a broad range of Froude number. The flow rate was measured using flow meter (Rotameter type), attached to the supply line of the flume for maximum capacity 102.5 $\mathrm{m}^{3} / \mathrm{hr}$. The depth of water was measured using a vernier point gauge with $0.1 \mathrm{~mm}$ accuracy. The local flow velocity was measured by using a propeller current meter mounted on a wading rod gage. When the propeller rotates the number of revolutions in a given time is counted on a digital counter panel every 10 second, and recorded in Hertz. The average was taken from the recorded data after nearly constant readings. Then the flow velocities obtained after converting the average "Hertz" reading to velocity in $\mathrm{cm} / \mathrm{s}$ by using an appropriate relationship which was prepared by authors after extracted data from chart issued by "Nixon" company, the manufacturer of the device. Three groups of stiff waterproof rubber cube were used as a roughness element appurtenance in the stilling basin and its dimensions shown in Fig.1.

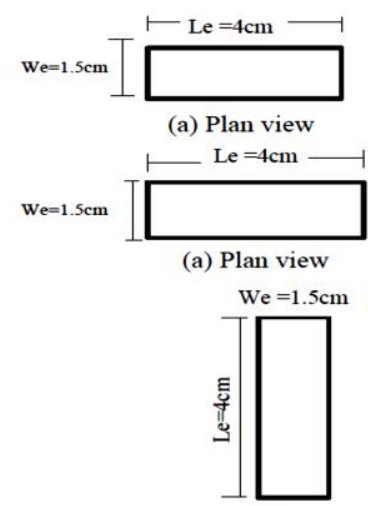

(a) Plan view

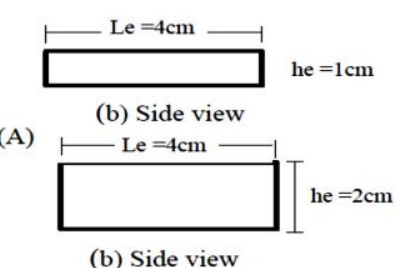

(B)

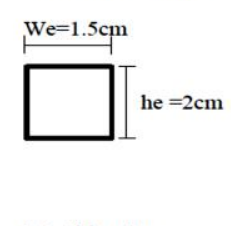

(b) Side view
Fig. 1. Dimensions of the group of cubic roughness element

Different roughness intensities were considered by using these three groups. The percent roughness intensity (I) is defined as the ratio between the projected area, and the total area of the basin covered by roughness was calculated by; 
Where: $\mathrm{I}=$ percentage intensity of elements in the basin,

$\mathrm{B}=$ width of the basin,

$\mathrm{Lr}=$ length of roughened bed,

$\mathrm{a}=\mathrm{is}$ a plane area of one element, and

$\mathrm{N}=$ the number of roughness elements.

The first row of cube elements was at a distance of $18 \mathrm{~cm}$ downstream from the gate $(10 \mathrm{~cm}$ from the beginning of the basin) followed by the other rows up to the desired length of roughness that gives required intensity. The crest levels of elements at the same level of the upstream bed that gives a non-protruding feature inside the basin to overcome the phenomenon of cavitation. The elements being depress, increase bed shear, thereby, creating more turbulence. The three different configuration groups were installed to show the effect of length, (Le), width, (We) and height, (he) as well as the intensity of these elements on the hydraulic jump characteristics and stilling basin performance. The information about the geometrical characteristics of the three groups of roughness elements and their configurations are listed in Table 1.

After analyzing the results of both groups A and B it was found the best bed roughness intensity was at $\mathrm{I}=12 \%$, that was recorded by configuration B3. The more dissipation of energy by reducing the sequent depth and lesser length of the hydraulic jump were achieved with this configuration. Accordingly, third group $\mathrm{C}$ was conducted with the best intensity $(\mathrm{I}=12 \%)$, and the variation was adopted to show the effect of the element width and length relative to its height on the hydraulic jump characteristics. The arrangement of $\mathrm{C} 1$ is shown in Fig.2.

\section{Results and discussion}

The study included fifty one experiments conducted for a basin with the three groups consisting of different configurations and arrangements of roughness elements. As mentioned previously, all of these configurations were used to investigate their impact on hydraulic jump performance specifically on its properties such as; depth ratio (sequent depth to initial depth), energy loss, and gain in energy dissipation. The comparison between groups of roughness elements depends on the benefits which arise from usage. The streamlined lib sluice gate opening refers to the initial depth of the hydraulic jump, y1 ranging between $1 \mathrm{~cm}$ to $4 \mathrm{~cm}$ to achieve the incoming Froude number, Fr1 between 9.2 to 2.7 at which the operation discharge for this achievement was ranged between $30.61 \mathrm{~m}^{3} / \mathrm{hr}$ to $72.47 \mathrm{~m}^{3} / \mathrm{hr}$ respectively.
Table 1. Geometrical characteristic of the roughness element configurations

\begin{tabular}{|c|c|c|c|c|c|c|c|}
\hline Group & \multirow[t]{2}{*}{ Config. } & \multirow{2}{*}{$\begin{array}{c}\text { Element } \\
\text { No. }\end{array}$} & \multirow{2}{*}{$\begin{array}{l}\text { No.of } \\
\text { runs }\end{array}$} & \multirow[t]{2}{*}{ I } & \multicolumn{3}{|c|}{$\begin{array}{c}\text { Dimensions } \\
(\mathrm{cm})\end{array}$} \\
\hline \multirow{5}{*}{ A } & & & & & he & Le & we \\
\hline & $\mathrm{A} 1$ & 40 & 6 & $8 \%$ & 1 & 4 & 1.5 \\
\hline & $\mathrm{A} 2$ & 50 & 6 & $10 \%$ & 1 & 4 & 1.5 \\
\hline & $\mathrm{A} 3$ & 60 & 6 & $12 \%$ & 1 & 4 & 1.5 \\
\hline & A4 & 80 & 6 & $16 \%$ & 1 & 4 & 1.5 \\
\hline \multirow{4}{*}{ B } & B1 & 40 & 6 & $8 \%$ & 2 & 4 & 1.5 \\
\hline & B2 & 50 & 6 & $10 \%$ & 2 & 4 & 1.5 \\
\hline & B3 & 60 & 6 & $12 \%$ & 2 & 4 & 1.5 \\
\hline & B4 & 80 & 6 & $16 \%$ & 2 & 4 & 1.5 \\
\hline $\mathrm{C}$ & $\mathrm{C} 1$ & 60 & 3 & $12 \%$ & 2 & 1.5 & 4 \\
\hline
\end{tabular}

Table 1. Continued

\begin{tabular}{|c|c|c|c|c|}
\hline We/he & Le/he & No.of rows & No.of col. & X1 (cm) \\
\hline 1.5 & 4 & 5 & 8 & 7.25 \\
\hline 1.5 & 4 & 5 & 10 & 5 \\
\hline 1.5 & 4 & 5 & 12 & 3.5 \\
\hline 1.5 & 4 & 5 & 16 & 1.62 \\
\hline 0.75 & 2 & 5 & 8 & 7.25 \\
\hline 0.75 & 2 & 5 & 10 & 5 \\
\hline 0.75 & 2 & 5 & 12 & 3.5 \\
\hline 0.75 & 2 & 5 & 16 & 1.62 \\
\hline 2 & 0.75 & 5 & 12 & 6 \\
\hline
\end{tabular}

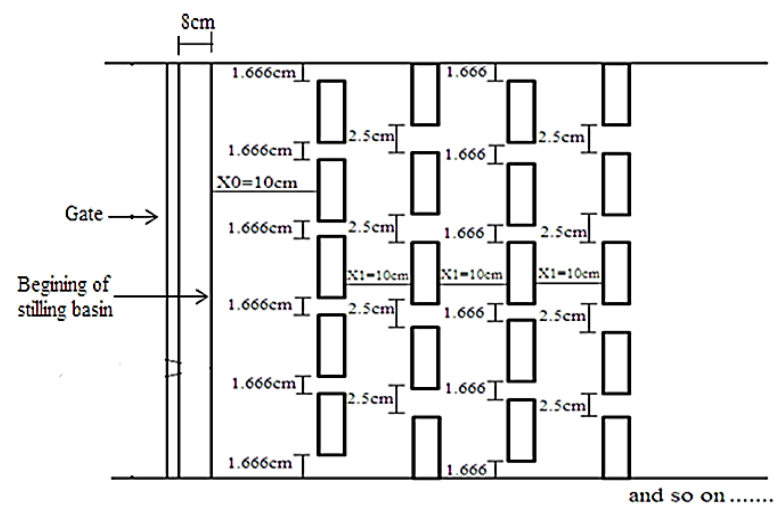

Fig. 2. Plan view arrangement of the configuration $\mathrm{C} 1$ at best intensity $\mathrm{I}=12 \%$.

The effect of We/he and Le/he as well as the intensity of roughness elements on the sequent depth ratio was determined. The variation of $\mathrm{y} 2 / \mathrm{y} 1$ when using models of group $\mathrm{A}(\mathrm{We} / \mathrm{he}=1.5, \mathrm{Le} / \mathrm{he}=4)$ and Group $\mathrm{B}(\mathrm{We} / \mathrm{he}=0$. 75, Le/he=2) was sketched with Fr1 as shown in Figs.3 and 4 . 


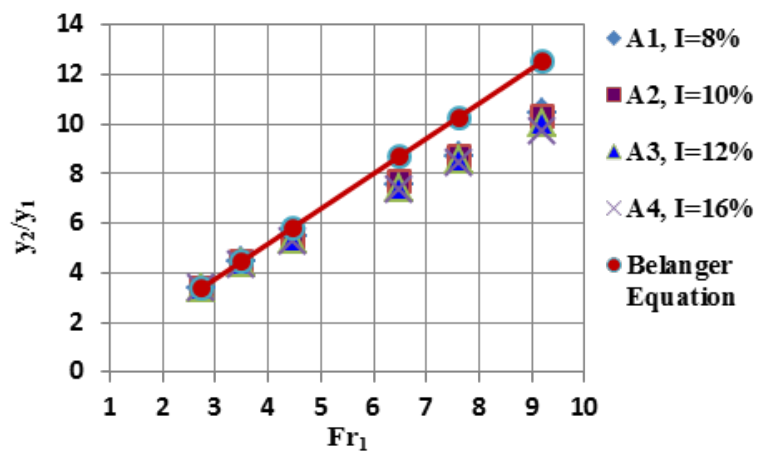

Fig. 3. Variation of $y 2 / y 1$ for group A

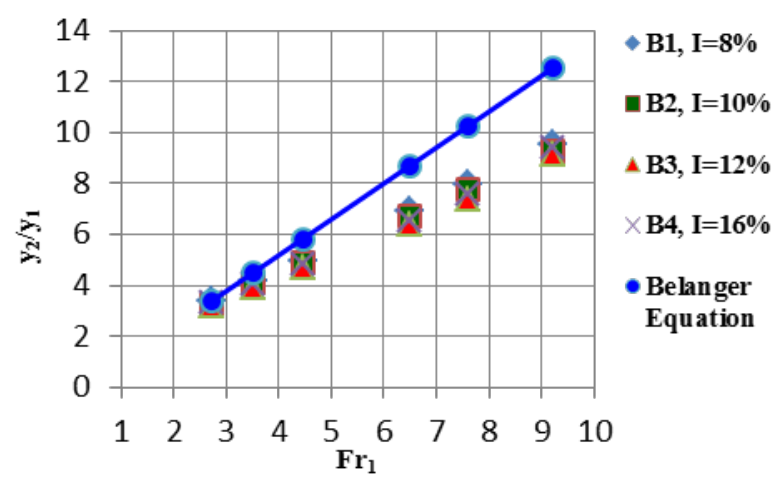

Fig. 4. Variation of $y 2 / y 1$ for group $B$

These figures illustrate that the sequent depth ratio for both groups roughness $\mathrm{A}$ and $\mathrm{B}$ are smaller than that for classical jump (Belanger equation). Also as can be observed the variation of intensity does not have an appreciable effect on depth ratio. While for the same intensity the decrease of We/he and Le/he has an effect on decreasing the values of $y 2 / y 1$ that can be achieved when the height of roughness elements increased. The best roughness intensity was $\mathrm{I}=12 \%$ with model $\mathrm{B} 3$, where the minimum sequent depth ratio was achieved as depicted in Fig.4. To study the effect of width/height and length/height ratios of roughness elements a comparison between configuration $\mathrm{B} 3$ and configuration $\mathrm{C} 1$ (which have the same intensity and roughness height) was conducted. Fig.5 shows the variations of sequent depth ratio as affected by the two geometric ratios of elements. This figure demonstrates clearly that the performance with B3 was better as compared to configuration $\mathrm{C} 1$. Moreover, the visual observation shows that the better stability of jump was achieved by using B3 model. The comparison with previous results presented by some researches, at hand, is illustrated in Fig.6. In this figure the results of work done by [5] who used staggered roughness with $\mathrm{W} / \mathrm{L}=4, \mathrm{~W} / \mathrm{Z}=6$ where $\mathrm{W}$ is the longitudinal spacing between two roughness elements in successive rows, $\mathrm{L}$ is the length of the roughness element, and $\mathrm{Z}$ is the height of the roughness element, [3] whose used lozenge roughness shape, [25] whose used two types of natural bed roughness with crushed sedimentation materials 20 and $27 \mathrm{~cm}$ in size, and [11] whose used U-shaped roughness elements.

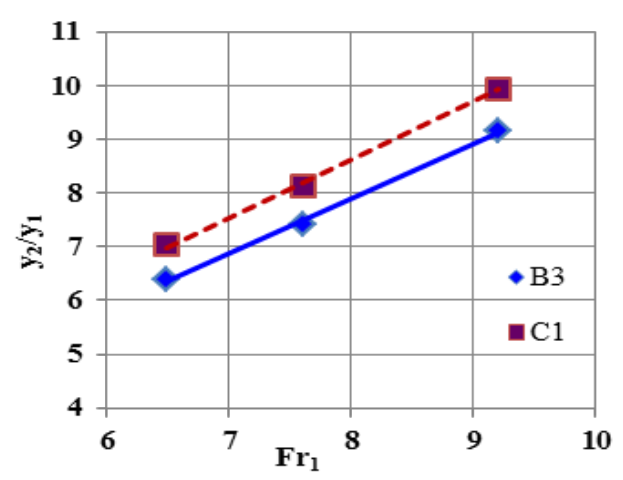

Fig. 5. Effect of width and length to height of roughness element

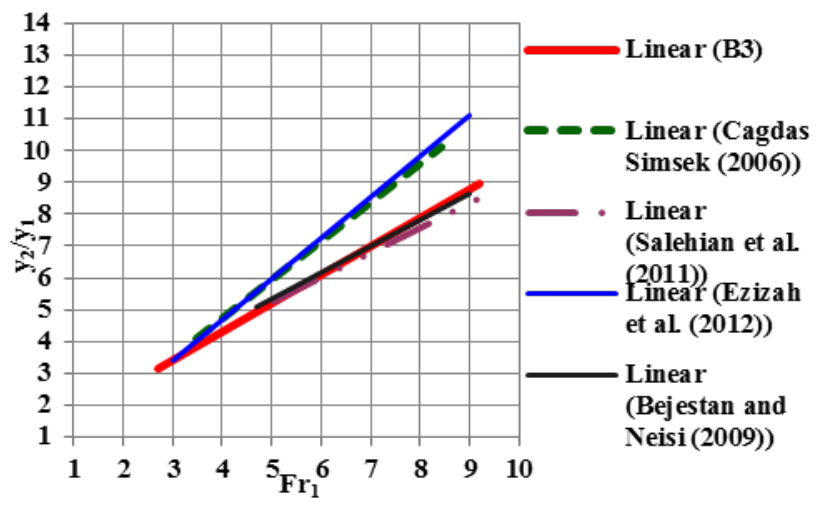

Fig. 6. Effect of B3 on $y 2 / y 1$ as compared with the results of previous studies

This comparison sketched as one set of data together with configuration B3. The trend curves in the figure illustrate that $\mathrm{B} 3$ gives a higher reduction in y 2 compared to the results of [5] and [11], but gives approximately the same effect on the sequent depth y2 as compared to the results of [3] and [25]. In order to show the amount of difference between the sequent depth of forced jump y2 and sequent depth of classical jump y $2 *$, a dimensionless depth deficit parameter $\mathrm{D}$ was used. This parameter indicator was adopted previously by numerous researchers such as [8], [17], [26], [1], and [9] as given below:

$$
D=\frac{y_{2}^{*}-y_{2}}{y_{2}^{*}}
$$

Eq. 2 refers that, the higher the D, the lower sequent depth that is associated with a specified configuration. Accordingly, Depth deficit parameter D was computed for all configurations of groups $\mathrm{A}$ and $\mathrm{B}$ roughness elements and listed in Table 2. The last column in the table refers to the required tail water that needs to achieve a sequent depth, y2 as compared with that 
calculated by Belanger equation. Fig. 7 shows the trend variation of $\mathrm{D}$ with Fr1 for all configurations and the higher deficit parameter was recorded with configuration B3. Comparison of the depth deficit parameter that corresponding with configuration B3 of the present study with those proposed by previous studies shows that: the average value with staggered rough elements of $\mathrm{W} / \mathrm{L}=4$ and $\mathrm{W} / \mathrm{Z}=6$ was $\mathrm{D}=0.11$ which introduced by [5], whereas the mean value of $D=0.2$ was found with configuration $\mathrm{B} 3$ and is close to the average value of $\mathrm{D}=$ 0.19 which obtained by [25] for crushed gravel materials $27 \mathrm{~mm}$ in size.

Table 2. Average value of $\mathrm{D}$ and Percent reduction of $\mathrm{y} 2$

\begin{tabular}{|c|c|c|c|c|c|}
\hline 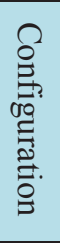 & $\begin{array}{l}\text { he } \\
(\mathrm{cm})\end{array}$ & We/he & Le/he & $\begin{array}{c}\text { Average } \\
\text { value of } \\
\text { D }\end{array}$ & $\begin{array}{l}\text { The } \\
\text { sequent } \\
\text { depth } \\
\text { required } \\
\text { for forced } \\
\text { jump }\end{array}$ \\
\hline A1 & 1 & 1.5 & 4 & 0.09 & $0.91 \mathrm{y}_{2}{ }^{*}$ \\
\hline $\mathrm{A} 2$ & 1 & 1.5 & 4 & 0.09 & $0.91 y_{2}{ }^{*}$ \\
\hline A3 & 1 & 1.5 & 4 & 0.10 & $0.90 y_{2}{ }^{*}$ \\
\hline A4 & 1 & 1.5 & 4 & 0.12 & $0.88 \mathrm{y}_{2}{ }^{*}$ \\
\hline B1 & 2 & 0.75 & 2 & 0.15 & $0.85 \mathrm{y}_{2}{ }^{*}$ \\
\hline B2 & 2 & 0.75 & 2 & 0.17 & $0.83 \mathrm{y}_{2}{ }^{*}$ \\
\hline B3 & 2 & 0.75 & 2 & 0.20 & $0.80 \mathrm{y}_{2}{ }^{*}$ \\
\hline B4 & 2 & 0.75 & 2 & 0.18 & $0.82 \mathrm{y}_{2}{ }^{*}$ \\
\hline
\end{tabular}

In the present study, the measurements of the length of the jump Lj was considered as a longitudinal distance from the beginning of the jump to the section beyond it the water depth did not change. One of the major economic aims of the designer is to present the shortest stilling basin with the best hydraulic performance. The indicator of this goal is a decrease of the hydraulic jump length, $\mathrm{Lj}$. Thus, one of the advantageous of the appurtenances within a stilling basin is to achieve this aim. Based on that, the success model depends on how it performance close of the target.

Fig. 8 illustrates the relation between the initial Froude number and the length ratio of the jump $\mathrm{Lj} / \mathrm{y} 2 *$ for groups of roughness elements. The $\mathrm{We} / \mathrm{he}, \mathrm{Le} / \mathrm{he}$, as well as the intensity, have been selected as the criteria to show their effects on the length of the jump. It is seen from figure that all configurations of group A have a slightly effect on the length ratio of the jump. While for group B, the increase in intensity caused an appreciable effect in the reduction of the length of hydraulic jump and the maximum reduction was at $\mathrm{I}=12 \%$. That achieved with configuration B3. Fig.9 shows the comparison between the results of configuration B3 with results proposed by
[5] for staggered roughness and [25] for crushed gravel materials $27 \mathrm{~mm}$ in size. It seems from this figure that the performance of B3 gives the best results in reducing the length of the jump compared to those staggered by previous researchers.

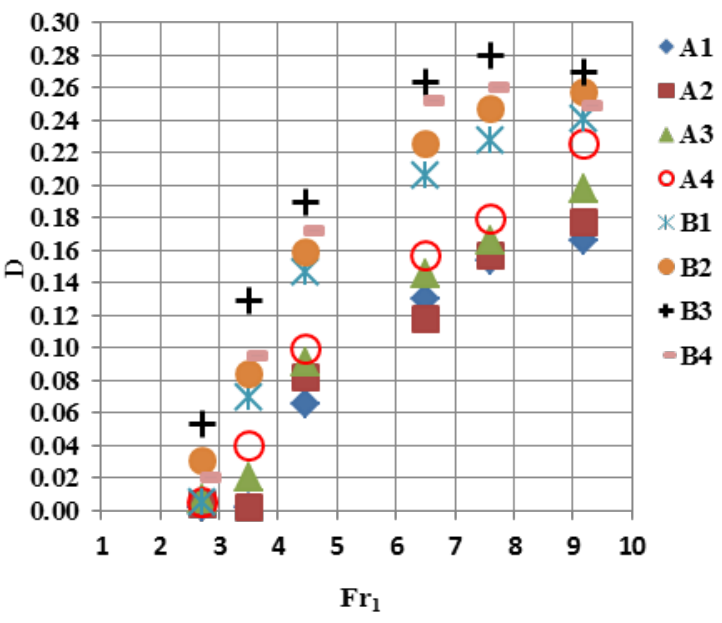

Fig. 7. Relationship between D and Fr1

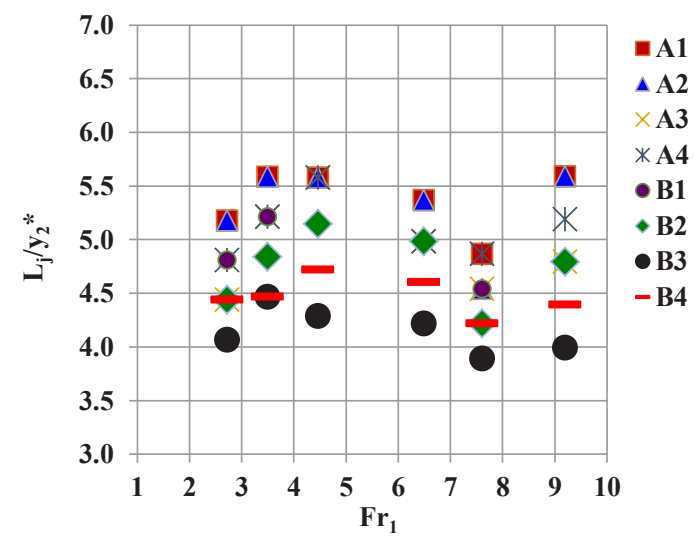

Fig. 8. Effect of different configuration of roughness elements on jump length

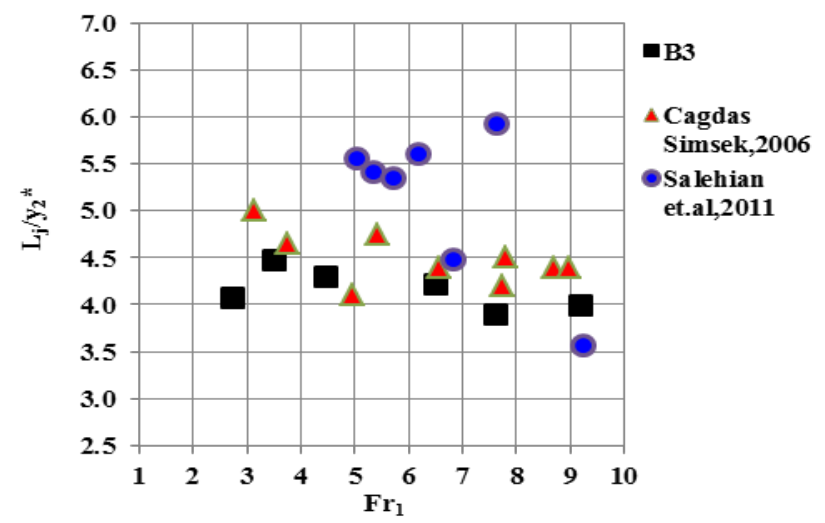

Fig. 9. Comparing the results of model B3 with previous studies 
Energy dissipation ratio, $\Delta \mathrm{E} / \mathrm{E} 1$, is the difference between the specific energies before and after the hydraulic jump relative to the initial energy. The $\Delta \mathrm{E}$ hence, reflect the amount of energy lost through the jump when the flow passes from supercritical to subcritical. To determine the effect I, We/he, and Le/he on the energy dissipation ratio, each criterion of these parameters is individually tested as given below;

Fig.10 represents the variation of, $\Delta \mathrm{E} / \mathrm{E} 1$ with the change of intensity of roughness at different Froude numbers for configurations of group A. It was found in the nature of the spread of the data points that, the variation in intensity does not have a significant effect on the rate and amount of energy dissipation along the jump.

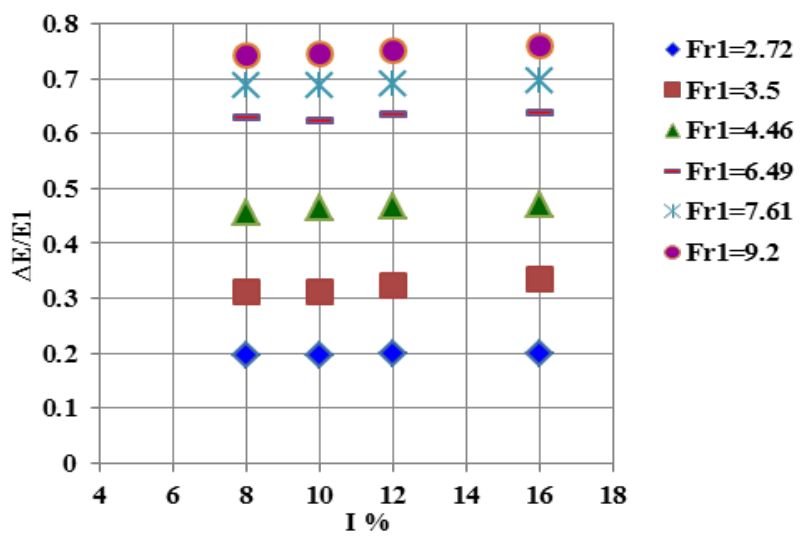

Fig. 10. Variation of $\Delta \mathrm{E} / \mathrm{E} 1$ with I for group A configuration

The change of $\Delta \mathrm{E} / \mathrm{E} 1$ as $\mathrm{We} / \mathrm{he}$ changed for the roughness intensity $(\mathrm{I}=12 \%)$ with different Froude numbers, is shown in Fig.11. It can be concluded from this figure that the We/he has a significant effect on the rate of energy dissipation. The upper and lower dissipation of energy has been recorded with $\mathrm{We} / \mathrm{he}=0.75$ and 1.5 respectively.

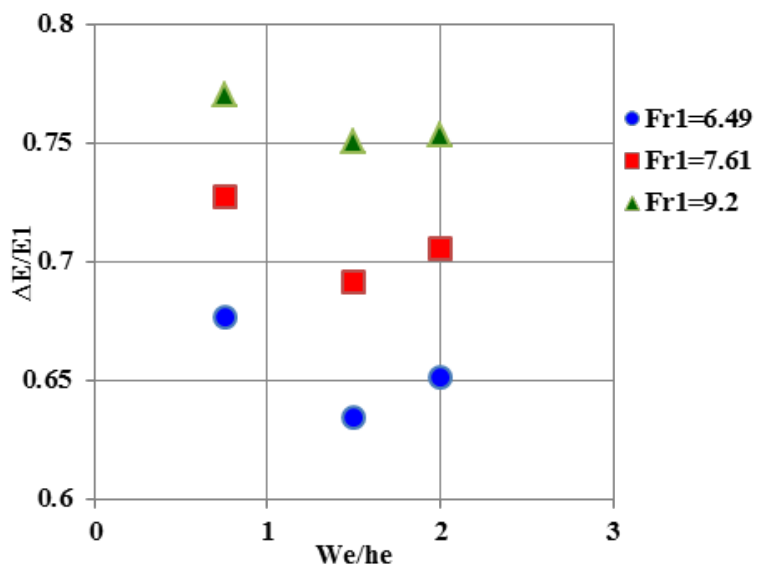

Fig. 11. Effect of $\mathrm{W}_{\mathrm{e}} / \mathrm{h}_{\mathrm{e}}$ on energy dissipation
The variation of $\Delta \mathrm{E} / \mathrm{E} 1$ with $\mathrm{Le} /$ he for the roughness intensity $(\mathrm{I}=12 \%)$ and Froude number ranged between 6.49 and 9.2, is shown in Fig.12. This figure indicates that the length of roughness elements relative to its height has a significant effect on the dissipation of energy. The higher dissipation of energy occurred with Le/he $=2$.

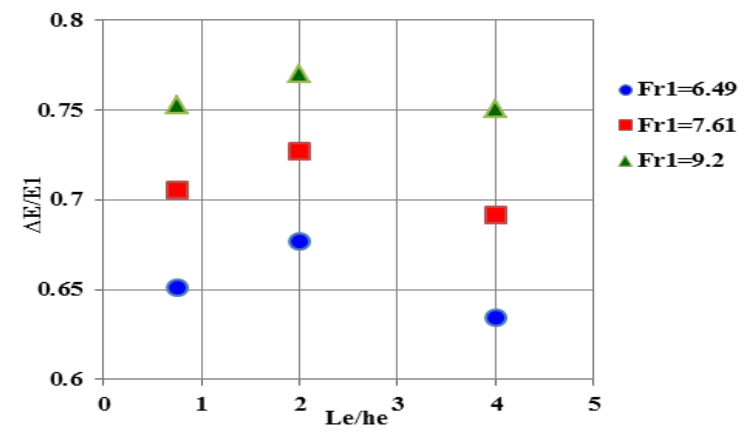

Fig. 12.Effect of $L_{e} / h_{e}$ on energy dissipation

Fig. 13 introduces the relationship between the relative energy losses, $\Delta \mathrm{E} / \mathrm{E} 1$ as the dependent variable with Froude number for different configurations of roughness elements. As mentioned previously, the variation in the intensity has no significant effect on the rate of energy dissipation along the jump, while the change in $\mathrm{We} / \mathrm{he}$ and Le/he has an appreciable effect. However, the best configuration affected the hydraulic performance was $\mathrm{B} 3$, where the energy dissipation was from $22.6 \%$ to $77 \%$.

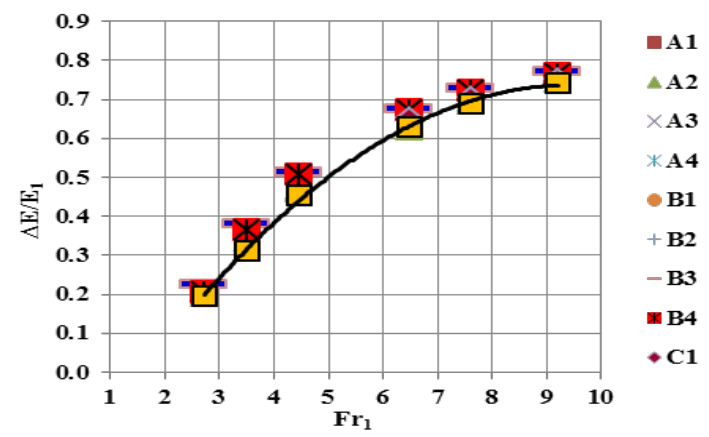

Fig. 13. Relationship between $\Delta \mathrm{E} / \mathrm{E} 1$ and $\mathrm{Fr} 1$ for all roughness elements

The effect of incoming Froude number is evident on energy dissipation rate. Thus the energy dissipation is basically a function of the initial Froude number Fr1. Based on this concept the relationship between the rate of energy dissipation $\Delta \mathrm{E} / \mathrm{E} 1$, and the Froude number Fr1, at different configurations of roughness elements is defined by the following equation with $\mathrm{R}^{2}$ equals 0.999 . It should be referred that Eq.3 can be used with all Froude numbers ranging between 2.72 and 9.2. The 
general view of jump with using the configuration B3 as roughness elements on bed of stilling basin is shown in Fig.14.

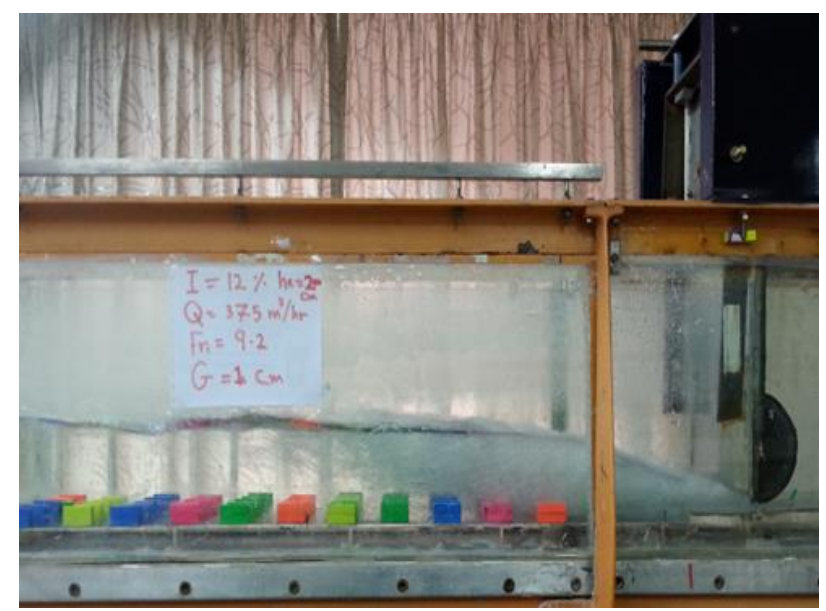

Fig. 14. General view of jump with using the configuration B3>

$$
\frac{\Delta E}{E 1}=-0.0112 F r_{1}^{2}+0.223 F r_{1}-0.321
$$

The gain in energy dissipation can be defined as the percent of the additional dissipation of energy (when the jump forced by confining it within a stilling basin equipped with baffled appurtenances) to the energy which was dissipated by the hydraulic jump when occurred on a smooth bed (free jump) under identical upstream flow conditions. This parameter was adopted previously by numerous researchers [e.g., 10,27 and 1] it can be expressed as;

$$
G_{E D}=\frac{\Delta E-\Delta E^{*}}{\Delta E^{*}} * 100
$$

Where:

$\Delta \mathrm{E}=$ is the energy loss for a jump formed in a rough bed (forced jump).

$\Delta \mathrm{E}^{*}=$ is the energy loss for a jump that occurs on a smooth bed (free jump).

To determine the effects of I, We/he, as well as Le/he on the gain in energy dissipation, the influence of these parameters individually has been investigated as follows;

Fig.15 illustrates the variation of gain in energy dissipation \%GED with the intensity of roughness elements I for the Froude number ranging between 2.72 to 9.2 when group $\mathrm{A}$ used. It seems from this figure that the variation of roughness intensity has a significant effect on the gain of energy for the same $\mathrm{We} / \mathrm{he}$ and Le/he (i.e., for the same configuration).

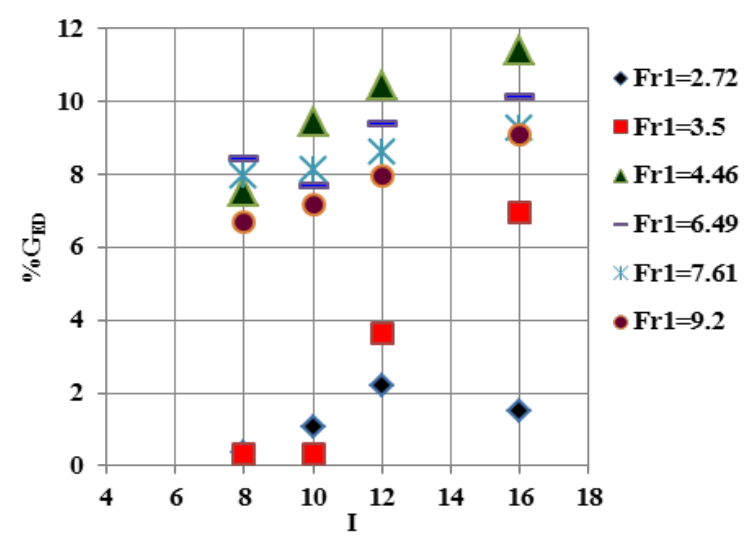

Fig. 15. Effect of intensity on the gain of energy dissipation when group A used

The effect of We/he when the roughness intensity (I=12\%) on \%GED for Froude number ranged between 6.49 and 9.2, is shown in Fig.16. It can be concluded from this figure that the variation in the $\mathrm{We} /$ he has a high effect on the gain of energy dissipation. A higher gain was recorded with $\mathrm{We} / \mathrm{he}=0.75$.

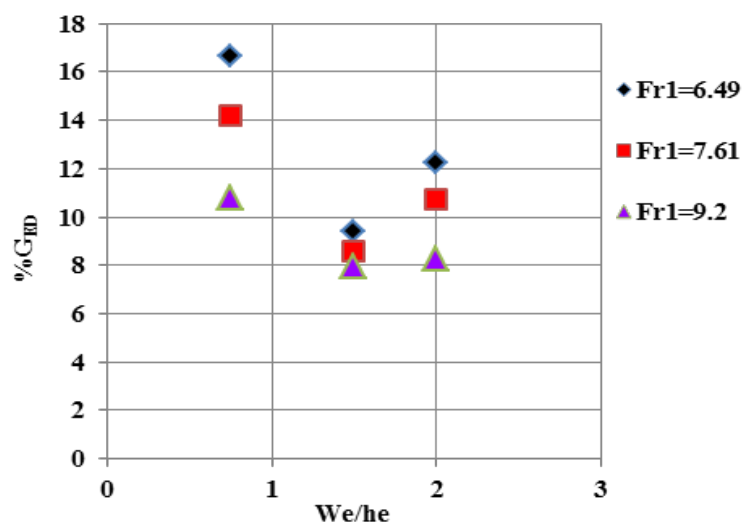

Fig. 16. Effect of $\mathrm{W}_{\mathrm{e}} / \mathrm{h}_{\mathrm{e}}$ on the gain of energy dissipation

The variation of \%GED with Le/he for the same roughness intensity $(\mathrm{I}=12 \%)$ and the same range of Froude number (6.49-9.2), is shown in Fig.17. The trend of points in this figure generally shows that the length of the element is directly influenced by the advantageous gain of energy dissipation, and when Le/he $=2$ a higher dissipation occurred that indicated to a higher percentage of energy gained with this dissipation.

The variation of percent gain in energy dissipation for various configurations of roughness elements is presented in Fig.18. The trends of data points and values confirm that the Configuration B3 is the best in terms higher gain in energy dissipation as compared to other configurations. The gain in energy in case of B3 ranged between $10.8-22.3 \%$ larger than that resulted in the free jump. 


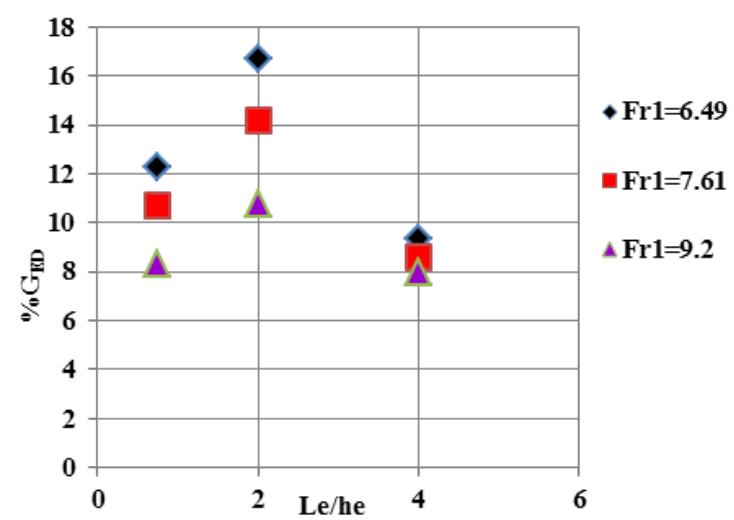

Fig. 17. Effect of $\mathrm{L}_{\mathrm{e}} / \mathrm{h}_{\mathrm{e}}$ on the gain of energy dissipation

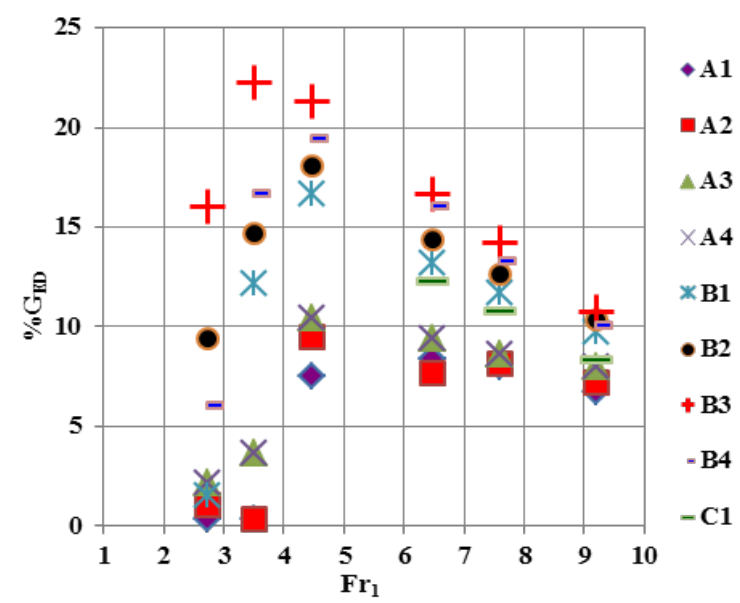

Fig. 18. Percent gain of energy with all configurations of roughness elements

\section{Conclusions}

Experimental tests were performed for hydraulic jump stilling basin by adopting three groups of roughness elements installed on a bed of the basin at non-protruding arrangement including numerous configurations at different intensity, width of the element to its height (We/he) and length of the element to its height (Le/he). The types of hydraulic jump were bounded for the incoming Froude number, Fr1 between 2.72 and 9.2. The data thus collected it was processed analytically and the results of the analysis presented in numerous figures. The best configuration of roughness elements that which give minimum sequent depth was B3. The higher reduction in y2/y1 associated with this configuration was $20 \%$ compared with a classical jump (Belanger equation). The length ratio of hydraulic jump $\mathrm{Lj} / \mathrm{y} 2 *$ for all configurations of roughness elements located below the limitation curve that presented [23]. It was also found that the configuration $\mathrm{B} 3$ was more effective in reducing the jump length. One of the most parameters used as an indicator of a beneficial performance of hydraulic jump is the dissipation of kinetic energy. Accordingly, the relative energy dissipation $\Delta \mathrm{E} / \mathrm{E} 1$ for all configurations was tested. It was found that the variation in intensity does not have a significant effect on the amount of energy dissipation along the jump, while the change in $\mathrm{We} / \mathrm{he}$ and Le/he have significant effects on the rate of energy dissipation. However, the higher dissipation of energy has been recorded with $\mathrm{We} / \mathrm{he}=0.75$ and Le/he $=2$. This arrangement is for configuration B3. Also more gain in energy dissipation \%GED was associated with configuration $\mathrm{B} 3$, which ranged between $10.8-22.3 \%$.

The authors are grateful to the Directorate of Laboratory in Building and Construction Eng. Dep. for approval to use flume and measurement facilities. Appreciation is due to the staff member of Hydraulic Laboratory for assistance in preparing models. Deep acknowledgement is presented to the Building and Construction Engineering Department of the UOT, Iraq for academic assistance.

\section{References}

1. A. Abbaspour, A. Hosseinzadeh, D. Farsadizadeh, A. Sadraddini, J. Hydro-env. Res. 3,109-117 (2009)

2. J. AL-Baidhani, M.Sc. Thesis, Baghdad Univ, Irrigation and Drainage Engineering (1989)

3. M. Bejestan, K. Nesi, Asian J. of App. Sci., 2, 436-445 (2009)

4. J. Bradley, A. Peterka, 82,1401-1406 (1957)

5. S. Çagdas, M.Sc. Thesis, Middle East Tech. Univ., Dept. of Civil Eng., Ankara, Turkey (2006)

6. F. Carolo, V. Feroo, V. Pampalone, J. Hy. Eng., ASCE, 133,989-999 (2007)

7. S. Chaurasia, J. Irr. and Drai. Eng., ASCE, 129, (2003)

8. S. Ead, N. Rajaratnan, J. Hy. Eng., ASCE, 128, 656663, (2002)

9. A. Ellayn, Zhi-lin SUN, J. of Zhejiang Univ.-Sci., 13, 519-525, (2012)

10. T. Evcimen, M.Sc. Thesis, Middle East Tech. Univ., Dept. of Civil Eng., Ankara, Turkey, (2005).

11. G. Ezizah, N. Yousif, S. Mostafa, Asian J. Appl. Sci., ISSN 1996-3343, DOI:10.3923, (2012)

12. W. Hager, R. Bremen, N. Kawagowshi, J. Hy. Res., 28, 591-608, (1990)

13. W. Hager, Kluwer Acad. Pub., Dordrecht, The Netherlands, (1992)

14. W. Hager, R. Bremen, J. Hy. Res., 27, 565-585, (1989)

15 W. Hughes, J. Flack, J. Hy. Eng., 110, 1755-1771, (1984)

16. F. Izadjoo, M. Bajestan, 17th Canadian, Hydrot. Conf., Hydrot. Eng., Edmonton, Alberta, Canada, Aug. 17-19, (2005) 
17. F. Izadjoo, M. Bajestan, J. App. Sci., 7, 1164-1169, (2007)

18. A. Kazemiyanzadeh, M. Bajestan, $3^{\text {rd }}$ Conf. mang. of Iran's water res., Tariz, (2008)

19. H. Leutheusser, V. Kartha, J. Hy. Eng., 98, $1367-$ 1383, (1972)

20. H. Mohamed Ali, J. Hy. Eng., 117, 83-93, DOI:10.1061/(ASCE)0733-9429(1991)117:1(83), (1991) 21. A. Negm, $5^{\text {th }}$ Int. Conf. on Hydro-Sci. and Eng., Warsaw, (2002)

22. I. Ohtsu, Y. Yasuda, J. Hy. Eng., ASCE, 120, (1994)

23. A. Peterka, Eng. Monograph No. 25. USBR, Denver, USA, (1958)

24. N. Rajaratnam, K. Hurtig, J. Hy. Eng., 126, 310-12, (2000)

25. S. Salehian, M. Bajestan, H. Mousavi, H. Kashkhooli, S. Kashefipour, World Appl. Sci. J., 13, 1005-2011, (2011)

26. A. Samir, Final Res. Report No. 14/427, King Saud Univ., Collegae of Eng. Res. Center (2007)

27. N. Tokyay, In Impacts of Global Climate Change Conf., EWRI, May, Alaska, USA, 408-416. DOI:10.1061/40792(173)408, (2005) 